
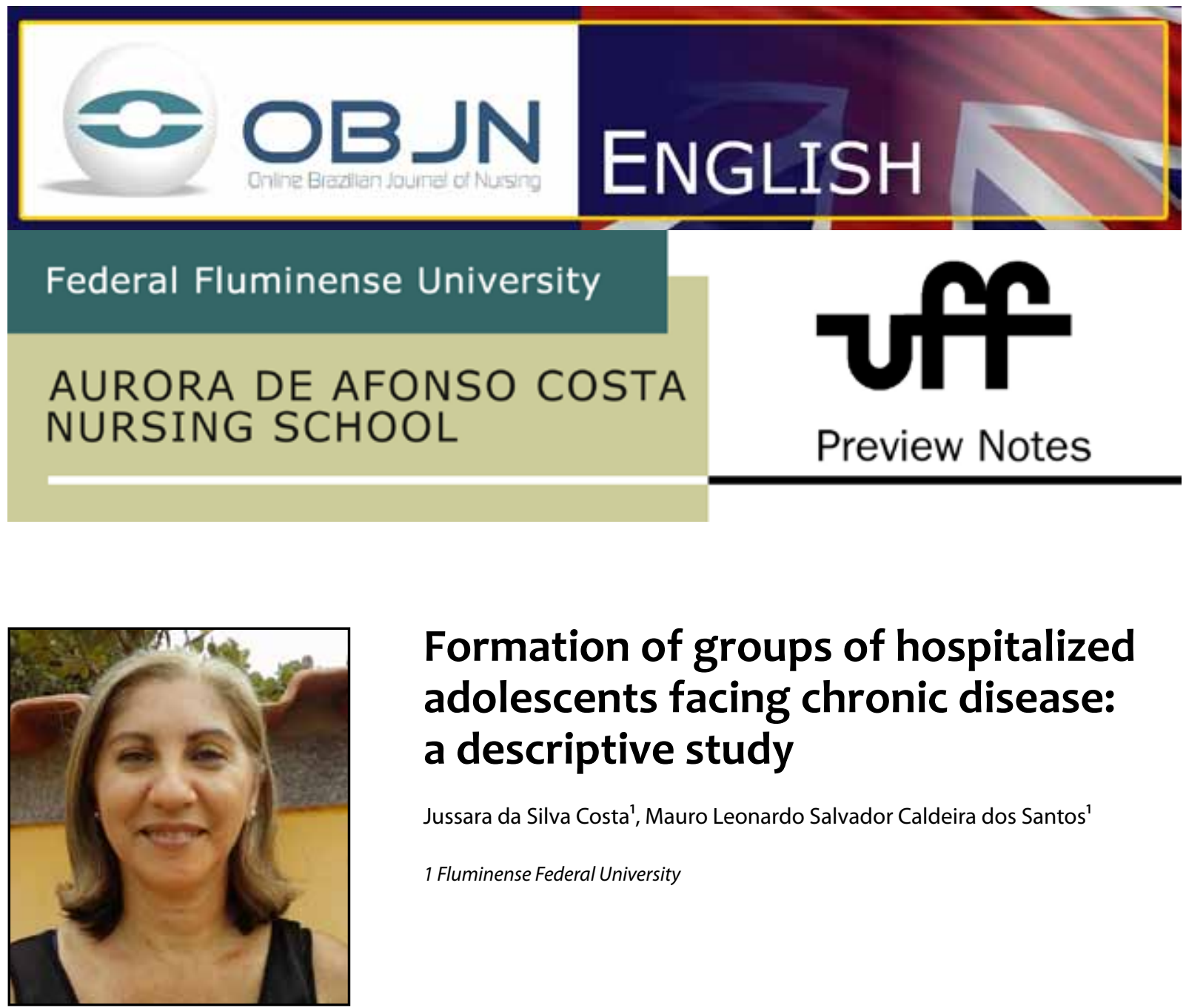

\title{
Formation of groups of hospitalized adolescents facing chronic disease: a descriptive study
}

\author{
Jussara da Silva Costa ${ }^{1}$, Mauro Leonardo Salvador Caldeira dos Santos ${ }^{1}$ \\ 1 Fluminense Federal University
}

\begin{abstract}
This is the dissertation project of the Professional Master's in Healthcare Nursing at Aurora de Afonso Costa School of Nursing / Fluminense Federal University. The topic is the changes in everyday life aspects of adolescents hospitalized with chronic non-communicable diseases (NCD). Aims: To analyze the process of group formation by listening to teenagers hospitalized with NCD as a tool for nursing care; to identify changes in the everyday lives of adolescents as a result of the impact of disease diagnosis, treatment and hospitalization; to discuss the strategies used to cope with the disease. Method: A descriptive exploratory study, to be conducted at a university hospital in the city of Niterói (RJ), with adolescents hospitalized with NCDs. Data collection will take place through the formation of groups containing at least two participants, guided by structured interview questions. Data will be treated by thematic content analysis.
\end{abstract}

Descriptors: Adolescent, Hospitalized; Chronic Disease; Nursing; Self-help Groups. 


\section{SITUATION AND ITS SIGNIFICANCE}

Chronic non-communicable diseases (NCD) in adolescence causes changes in daily life in terms of treatment, hospitalization, distress and limitations. The therapy can be long; they have to deal with pain; there are invasive procedures; there is the separation from everyday routine involving the family and school; and there may be changes in teenagers' self-image that can generate fear, insecurity, apathy, anger and denial. Teenagers usually live for the present, and adapting to this new condition can be complex; so it's important to bring them to a new understanding of reality ${ }^{(1)}$. Over the past 30 years, technological advances have lead to increased survival and quality of life of people with NCDs. In developed countries, it is estimated that $10-20 \%$ of all children and adolescents suffer from an NCD and that more than $85 \%$ survive to adolescence.

Youth is, in general terms, multifaceted. The stages of adolescence are influenced by their different development processes and training. The socio-cultural environment, beliefs, values, habits - i.e., the culture - is clearly a determining factor in how teenagers see themselves, relate to others and guide their life towards adulthood ${ }^{(2)}$. When group activities are developed correctly in the environment in which they live, and healthy relationships are seen as potential tools for a more productive service, this can be a unique moment for the patient to answer questions and share experiences. It is a privileged place for the exchange and expression of individuality, change and growth. In this regard, special attention should be given to the group through a qualified hearing of their expressed or latent needs, promoting an education and supporting their space ${ }^{(3)}$.

\section{GUIDING QUESTIONS}

- Which are the changes undergone in the everyday lives of adolescents hospitalized with NCDs?

- How does a teenager hospitalized with an NCD feel?

- How does the teenager face the changes in everyday life created by hospitalization?

\section{AIMS}

Main:

To analyze the process of the formation of the listening group with teenagers hospitalized with NCD as a tool for nursing care.

Specific:

To identify changes in the everyday lives of adolescents due to the impact of disease diagnosis, treatment and hospitalization;

To discuss the strategies used by the teenagers to cope with the disease.

\section{METHOD}

This is a descriptive, exploratory study with a qualitative approach of an action-research study type. It will be conducted in the pediatric ward of a university hospital in the city of Niterói (RJ). The ward has a total of 15 beds, and six of these are for children between 7 and 16 years. The subjects will be adolescents hospitalized with NCDs, with at least one previous hospitalization, aged between 12 and 16 years (an age range with a greater ability to express themselves and report their experience), of both genders. No specific kind of NCD was used as 
defining or exclusion criteria. Those who are confined to bed will be excluded from the study.

In the first step of the methodology, a survey of the admission of adolescents within the three years 2010-2013 will be undertaken in order to understand the profile of this population. Such data will be collected in the records of the appropriate departments of the hospital. Subsequently, five meetings will be held involving at least two participants, for the formation of the group. The meetings will take place in the afternoon, last an hour and begin in May 2014.

Data collection will be performed with the reading of a script containing predetermined questions. The group interview involves the following four steps:

1) Welcome: to start the group, the coordinator (researcher) makes a presentation;

2) Method: clarification on the process of group formation, goals and dynamics;

3) Immersion: questions about how teenagers think and feel about the change that hospitalization causes in their daily lives;

4) Evaluation: completion of the group interviews and reports about the technique. There will be a reporter who will make notes containing non-verbal information in a log; conversations will be recorded and fully transcribed.

The meetings will be held in a peaceful and private environment, free from outside noise. Group members are preferably sat in a circle so that everyone can look at each other. For data analysis, thematic content analysis will be used the stages are pre-analysis, material exploration and processing of the results. At the end of each meeting, a questionnaire will be distributed to evaluate the group activity and their participation. The study was approved by the Ethics and Research Committee of Antônio Pedro Hospital University under register number 611.195, on April $10^{\text {th }}, 2014$.

\section{REFERENCES}

1. Araújo YB, Collet N, Gomes IP, Amador DD. Saberes e experiências de adolescentes hospitalizados com doença crônica. Rev. enferm UERJ. 2011 abr/ jun; 19(2):274-9.

2. Beretta LL, Santos MLSC, Fuly PSC, Quintanilha BMD, Aquino JHW. Resilience in adolescents suffering from non-communicable diseases: a cross-sectional study. Online braz j nurs [Internet]. 2013 Dec [cited 2014 Sep 1]; 12(4):953-63 Available from: http://www.objnursing.uff.br// index.php/nursing/article/view/4481/html_27

3. Munari DB, Lucchesse R, Medeiros M. Reflexões sobre o uso de atividades grupais a portadores de doença crônica. Cienc Cuid Saude. 2009; 8 (supl): 148-154.

\begin{abstract}
All authors participated in the phases of this publication in one or more of the following steps, in According to the recommendations of the International Committee of Medical Journal Editors (ICMJE, 2013): (a) substantial involvement in the planning or preparation of the manuscript or in the collection, analysis or interpretation of data; (b) preparation of the manuscript or conducting critical revision of intellectual content; (c) approval of the versión submitted of this manuscript. All authors declare for the appropriate purposes that the responsibilities related to all aspects of the manuscript submitted to OBJN are yours. They ensure that issues related to the accuracy or integrity of any part of the article were properly investigated and resolved. Therefore, they exempt the OBJN of any participation whatsoever in any imbroglios concerning the content under consideration. All authors declare that they have no conflict of interest of financial or personal nature concerning this manuscript which may influence the writing and/or interpretation of the findings. This statement has been digitally signed by all authors as recommended by the ICMJE, whose model is available in http://www. objnursing.uff.br/normas/DUDE_eng_13-06-2013.pdf
\end{abstract}

Received: 08/12/2014
Revised: 09/24/2014
Approved: 09/26/2014 